\title{
Synergistic cytotoxic effects of a combined treatment of a Pinellia pedatisecta lipid-soluble extract and cisplatin on human cervical carcinoma in vivo
}

\author{
MINGXING ZHANG ${ }^{1,2}$, YI YU ${ }^{1,2}$, HONGWEI ZHANG ${ }^{1,2}$, HAIXIA HUANG $^{1,2}$, \\ QINGQING CAI ${ }^{1,2}$, YU KANG ${ }^{1,2}$, GUILING LI ${ }^{1,2}$ and CONGJIAN XU ${ }^{1-3}$ \\ ${ }^{1}$ Department of Integration of Western and Traditional Medicine, Obstetrics and Gynecology Hospital; ${ }^{2}$ Shanghai Key \\ Laboratory of Female Reproductive Endocrine Related Diseases, Fudan University, Shanghai 200011; \\ ${ }^{3}$ Institute of Biomedical Sciences, Fudan University, Shanghai 200032, P.R. China
}

Received August 8, 2015; Accepted January 26, 2017

DOI: $10.3892 / \mathrm{ol} .2017 .6091$

\begin{abstract}
Herbal medicines are known to have numerous benefits, including lower toxicity and fewer side effects than traditional chemotherapeutic drugs. In traditional Chinese medicine, the rhizome of Pinellia pedatisecta (PE) Schott has long been used to treat cancer, undiagnosed swelling and erythema toxicum. However, its medical benefits lack support from scientific evidence. A novel lipid-soluble extract from PE has been previously verified to enhance the cytotoxicity of cis-dichlorodiammineplatinum-II (CDDP) against human cervical cancer cells in vitro. The present study evaluated the synergistic cytotoxic effects of PE and CDDP against human cervical cancer. Combination therapy of PE with CDDP exhibited synergistic cytotoxicity towards CaSki cell growth in mouse xenograft tumors. PE exhibited a cytotoxic effect on tumor size and weight, although the inhibitory ratio of tumor weight was only $26.3 \%$ in the PE-treated group. However, when mice were co-treated with PE and CDDP, the inhibitory ratio was higher than that of mice treated with CDDP alone (50.8 vs. $68.4 \%$, respectively). The potential synergistic mechanism was likely via inhibiting the signaling E6/p53 pathway, restoring p53 function and inducing downstream tumor suppressor chain effects on apoptosis. Western blot analysis and immunohistochemistry indicated thatE6protein expression was significantly decreased upon treatment with combined PE and CDDP. The expression of p53 was increased in the combined PE and CDDP treatment group. Upregulation of p53-dependent apoptosis-associated proteins, including $\mathrm{Bcl}-2$-associated $\mathrm{X}$ protein and cleaved
\end{abstract}

Correspondence to: Dr Guiling Li or Dr Congjian Xu, Department of Integration of Western and Traditional Medicine, Obstetrics and Gynecology Hospital, Fudan University, 419 Fang-Xie Road, Shanghai 200011, P.R. China

E-mail: guilingli@fudan.edu.cn

E-mail: xucongjian@gmail.com

Key words: Pinelliapedatisecta Schott, cisplatin, cervical cancer, cytotoxicity, synergistic caspases-9 and -3 , was observed in the combined PE and CDDP treatment group. Our results present a molecular basis for the future application of the combination of PE and CDDP in the treatment of cervical cancer as a novel and pharmacologically safe chemotherapeutic strategy.

\section{Introduction}

Cervical cancer is the fourth most frequently diagnosed type of cancer among females worldwide, with $\sim 527,600$ new cases and 265,700 mortalities reported in 2012 worldwide (1). However, for patients with locally advanced stage disease and non-operable recurrence, platinum-based chemoradiotherapy remains the necessary curative therapy $(2,3)$. However, the chemotherapeutic use of platinum is limited by drug resistance and severe side effects $(4,5)$. Combinations of chemotherapeutic drugs with new anti-cancer agents are being investigated to improve clinical response.

Traditional Chinese medicine serves an important role in human health to prevent the development of certain diseases such as cancer. Pedate pinellia rhizome is a traditional Chinese medicine distributed in the central regions of China, which has been shown to be effective at treating $81.5 \%$ of the 247 cervical cancer cases treated in the Obstetrics and Gynecology Hospital of Fudan University in the 1970s (6). Initial in vitro studies on the active constituents of the plant demonstrated that the lipid-soluble fraction had the best inhibitory effect on the proliferation of cancer cells. Alkaloids, fatty acids and $\beta$-sitosterol were the predominant constituents of the lipid-soluble fraction of the plant (7). The present study investigated a novel lipid-soluble extract from Pinellia pedatisecta (PE), which was extracted by the Shanghai Institute of Materia Medica, Chinese Academy of Sciences (CAS) (8). Previous studies have evaluated the cytotoxic effect of PE in cervical cancer cells (8), and it was observed that PE could enhance the cytotoxicity of CDDP against human cervical cancer cells in vitro (9). However, little is known about the effect of $\mathrm{PE}$ on the efficacy of chemotherapeutic drugs in animal models. The present study aimed to assess the synergistic effect of PE when combined with CDDP on the human cervical cancer cell line 
CaSki in vivo. This combined treatment enabled a lower cytotoxic dose of CDDP without affecting its therapeutic effects. The detailed signaling pathway involved in the combined action of PE and CDDP in the human cervical cancer cell line CaSki in vivo is also discussed.

\section{Materials and methods}

Extraction of PE and preparation of PE solution. Dried rhizomes of PE Schott were obtained from Jinyao Ruida (Xuchang) Biology Technology Co., Ltd. (Zhengzhou, China) in June 2013 and were identified by Professor Jin-Gui Shen of the Shanghai Institute of Materia Medica, CAS (Shanghai, China). A voucher specimen was deposited at the Herbarium of Shanghai Institute of Materia Medica, CAS. The extracting technique and PE preparation process have been described in detail previously (8). Once prepared, $\mathrm{PE}$ was stored in a freezer at $-20^{\circ} \mathrm{C}$. Prior to use, $\mathrm{PE}$ was dissolved in dimethyl sulfoxide (DMSO) at a concentration of $20 \mathrm{mg} / \mu \mathrm{l}$ and stored at $4^{\circ} \mathrm{C}$. For animal experiments, a PE solution was freshly prepared by diluting the stock with $0.9 \%$ normal saline to the desired concentrations. DMSO (final concentration, $1 \%$ ) was used as a solvent control.

Cell culture and chemical reagents. The human cervical cancer cell line CaSki was obtained from the American Type Culture Collection (Manassas, VA, USA) and resuscitated by the Cell Bank, CAS. CaSki cells were then cultured at $37^{\circ} \mathrm{C}$ in a humidified $5 \% \mathrm{CO}_{2}$ atmosphere in Roswell Park Memorial Institute (RPMI)-1,640 medium (Gibco; Thermo Fisher Scientific, Inc., Waltham, MA, USA) with $10 \%$ fetal calf serum (Gibco; Thermo Fisher Scientific, Inc.), $100 \mathrm{IU} / \mathrm{ml}$ penicillin $\mathrm{G}$, and $100 \mathrm{mg} / \mathrm{ml}$ streptomycin sulfate (Sigma-Aldrich; Merck KGaA, Darmstadt, Germany). cis-Dichlorodiammineplatinum-II (CDDP) was purchased from Sigma-Aldrich (Merck KGaA). Rabbit monoclonal antibodies directed against p53 (2527), p21 Waf1/Cip1 (2947), p27 Kip1(3686s), apoptosis protease activating factor 1 (Apaf-1) (8969s), B cell lymphoma/leukemia-2 (Bcl-2) (9941), Bcl-2 associated X protein (Bax) (9942s), cleaved-caspase-9 (9501s), cleaved-caspase-3 (9664s) and GAPDH (2118) were purchased from Cell Signaling Technology, Inc. (Danvers, MA, USA). Mouse monoclonal antibody directed against human papilloma virus (HPV) E6 (sc-460) was provided by Santa Cruz Biotechnology, Inc. (Dallas, TX, USA). Rabbit monoclonal antibody against Ki-67 (ab16667) was also used (Abcam, Cambridge, UK).

Animal experiments. Athymic mice (BALB/c nu/nu, female; 16-18 g; 4-6 weeks old) were obtained from the Laboratory Animal Center of the Shanghai Institutes for Biological Sciences, CAS, and were raised in cages maintained at a temperature of $22 \pm 2^{\circ} \mathrm{C}$ and $65 \pm 5 \%$ humidity in a controlled animal facility with a 12-h light-dark cycle and ad libitum access to water in the Department of Laboratory Animal Science, Fudan University (Shanghai, China). All animal experiments were conducted in accordance with the internationally accepted principles for laboratory animal use and care, as described in the European Economic Community (EEC) guidelines (EEC Directive of 1986; 86/609/EEC) (10), and with approval from the Ethics Committee for Animal Experimentation of Fudan
University. CaSki cells (2x10 ${ }^{6}$ cells in $0.2 \mathrm{ml}$ of RPMI-1,640 without FCS) were subcutaneously injected into the right flank of the mice for tumor formation. When established tumors of $\sim 100$ $\mathrm{mm}^{3}$ in volume were detected, the mice were randomly divided into four groups (15 mice/group) and treated as follows: i) Solvent control; ii) PE at $10 \mathrm{mg} / \mathrm{kg} /$ day by gavage, as determined by a preliminary experiment (data not shown); iii) CDDP at $3 \mathrm{mg} / \mathrm{kg}$ every 3 days by intraperitoneal injection; and iv) combination of (ii and iii). Tumor volume was assessed every other day using a caliper, and was calculated as the (length $\mathrm{x}$ width) ${ }^{2} / 2$, where the width is the smallest measurement and the length is the longest measurement. After 3 weeks, half of the mice were killed, and the tumors were excised and weighed. The tumor inhibitory ratio was calculated using the following formula: Tumor inhibitory ratio $(\%)=[(\mathrm{C}-\mathrm{T}) / \mathrm{C}] \mathrm{x} 100$, where $\mathrm{C}$ is the mean tumor weight of the solvent control group and $\mathrm{T}$ is the mean tumor weight of the treated group. Tumor tissues were harvested for tissue processing. A 4-mm portion of each tumor was used to detect proteins using immunohistochemistry, and the remaining portion was frozen in liquid nitrogen for western blot analysis. The rest of mice were maintained until 70 days post-treatment, and mortality was recorded to obtain the survival curve of the mice.

Western blot analysis. To evaluate the expression of HPV E6, p53, p21, p27, Apaf-1, cleaved caspase-3, cleaved caspase-9, Bcl-2 and Bax proteins, $200 \mathrm{mg}$ of tissue was removed from liquid nitrogen and grounded into small pieces. The tissue was stirred in 10 volumes of lysis buffer $(50 \mathrm{mM}$ Tris- $\mathrm{HCl} \mathrm{pH} 7.4 ; 150 \mathrm{mM}$ $\mathrm{NaCl} ; 1 \%$ NP40; $0.25 \%$ Na-deoxycholate; 1 mM EDTA; 1 mM phenylmethane sulfonyl fluoride; and protease inhibitor cocktail) and centrifuged at $288 \times \mathrm{g}$ and $4^{\circ} \mathrm{C}$ for $20 \mathrm{~min}$. Concentration was determined using the Bio-Rad Protein Assay kit (Bio-Rad Laboratories, Inc., Hercules, CA, USA). The proteins were separated by SDS-PAGE with $30 \%$ acrylamide in the gel and then transferred onto polyvinylidene difluoride membranes. After blocking with 5\% non-fat dry milk in PBST (20 mM Tris-HCl, $150 \mathrm{mM} \mathrm{NaCl}$ and $0.05 \%$ Tween-20) for $1 \mathrm{~h}$ at room temperature, the membranes were incubated with primary antibodies at a 1:1,000 dilution overnight at $4^{\circ} \mathrm{C}$. Upon being washed with PBST three times, the membranes were incubated with horseradish peroxidase-conjugated goat anti-rabbit secondary antibodies (catalog no., 7170S; Cell Signaling Technology, Inc.) at a 1:1,000 dilution for $1 \mathrm{~h}$ at room temperature. The membranes were then washed with PBST three times for $60 \mathrm{~min}$. The specific HPV E6, p53, p21, p27, Apaf-1, cleaved caspase-3, cleaved caspase-9, Bcl-2 and Bax bands were developed using an enhanced chemiluminescent reagent (Pierce; Thermo Fisher Scientific, Inc.) and imaged by a gel scanner. The protein levels were normalized to GAPDH as reference.

Immunohistochemistry. Ki-67 and p53 expression was detected by immunohistochemistry. Paraffin-embedded tissue sections were deparaffinized by xylene, and sequentially rehydrated by 100,95 and $75 \%$ ethanol, followed by PBS. The antigen retrieval step was performed by heating the slides in citrate buffer for $25 \mathrm{~min}$ and then incubated with endogenous peroxidase blocking solution $\left(30 \% \mathrm{H}_{2} \mathrm{O}_{2}: \mathrm{CH}_{3} \mathrm{OH}=1: 9\right)$ for $30 \mathrm{~min}$. The slides were incubated with primary anti-Ki-67 (1:100) or anti-p53 (1:50) antibodies overnight at $4^{\circ} \mathrm{C}$, and PBS was used as a negative control. Then, the slides were incubated with 
peroxidase-conjugated anti-rabbit immunoglobulin $\mathrm{G}$ (catalog no., 8114P; Cell Signaling Technology, Inc.) for $30 \mathrm{~min}$. The staining reaction was performed with 3,3'-diaminobenzidine. Hematoxylin was used as a counter-stain to detect the nuclei, which were imaged with light microscopy.

Statistical analysis. Statistical analyses were conducted with SPSS 16.0 (SPSS Inc., Chicago, IL, USA). Data are expressed as the mean \pm standard deviation. Student's t-test was used for comparisons between groups. Kaplan-Meier analysis with a log-rank test was used to determine survival and differences between the control and treatment groups. $\mathrm{P}<0.05$ was considered to indicate a statistically significant difference.

\section{Results}

Synergistic inhibitory effects of $P E$ and $C D D P$ on subcutaneous xenografts in nude mice. None of the mice exhibited signs of physical discomfort during the treatment period (21 days). At the start of the treatment (day 0), the mean body weight of mice in the control and PE-treated groups was 18.0 and $17.7 \mathrm{~g}$, respectively. Following treatment, the mean body weight was 19.9 and $20.1 \mathrm{~g}$, respectively (day 21). Body weight stably increased in both groups (Fig. 1A). However, in the CDDP-treated group, the mice lost $25 \%$ of their body weight, while the mice in the combined PE and CDDP group lost $15 \%$ of their body weight. The CDDP-treated mice suffered a significant weight loss compared with that of the PE-treated and control mice $(\mathrm{P}<0.001)$. Although not significantly $(\mathrm{P}=0.24)$, the mice treated with CDDP lost more weight compared with mice undergoing combined treatment (Fig. 1).

Responses to the treatment regimen were monitored by assessing the tumor size. The initial xenograft volume in each group was $\sim 100 \mathrm{~mm}^{3}$. At the end of the treatment, the volume of the tumor mass was $489.5 \pm 157.1 \mathrm{~mm}^{3}$ in the control group, $369.1 \pm 157.1 \mathrm{~mm}^{3}$ in the PE-treated group, 288.8 $\pm 127.6 \mathrm{~mm}^{3}$ in the CDDP-treated group and $0.161 \pm 0.052 \mathrm{~mm}^{3}$ in the combined PE and CDDP-treated group (Fig. 2A and C). The mean weight of the resected tumor mass in the combined group was significantly lower than that of the groups treated with PE or CDDP alone (mean, $0.110 \pm 0.036 \mathrm{~g}$ vs. $0.256 \pm 0.045 \mathrm{~g}, \mathrm{P}<0.01$; and mean, $0.110 \pm 0.036$ g vs. $0.171 \pm 0.030 \mathrm{~g}, \mathrm{P}<0.05$, respectively) (Fig. 2B and C). PE slightly decreased the growth of human cervical cancer cells transplanted subcutaneously in female athymic mice, and the tumor weight inhibitory ratio was 26.3\%. With combined PE and CDDP treatment, the tumor weight inhibitory ratio increased to $68.4 \%$, which was higher than that of the CDDP-treated group (50.8\%).

$P E$ does not prolong the survival of tumor-bearing nude mice. PE did not significantly prolong survival in mice subcutaneously transplanted with the human cervical cancer CaSki cell line. Median survival time slightly increased from 38 days in the untreated control animals to 45 days in mice treated with $\mathrm{PE}(\mathrm{P}=0.15), 52$ days in mice treated with $\mathrm{CDDP}(\mathrm{P}=0.0011)$, and 60 days in mice treated with both $\mathrm{PE}$ and $\mathrm{CDDP}(\mathrm{P}<0.001)$ (Fig. 3). The survival of mice in the combined PE and CDDP treatment group was not longer than that of the CDDP-treated mice $(\mathrm{P}=0.22)$.
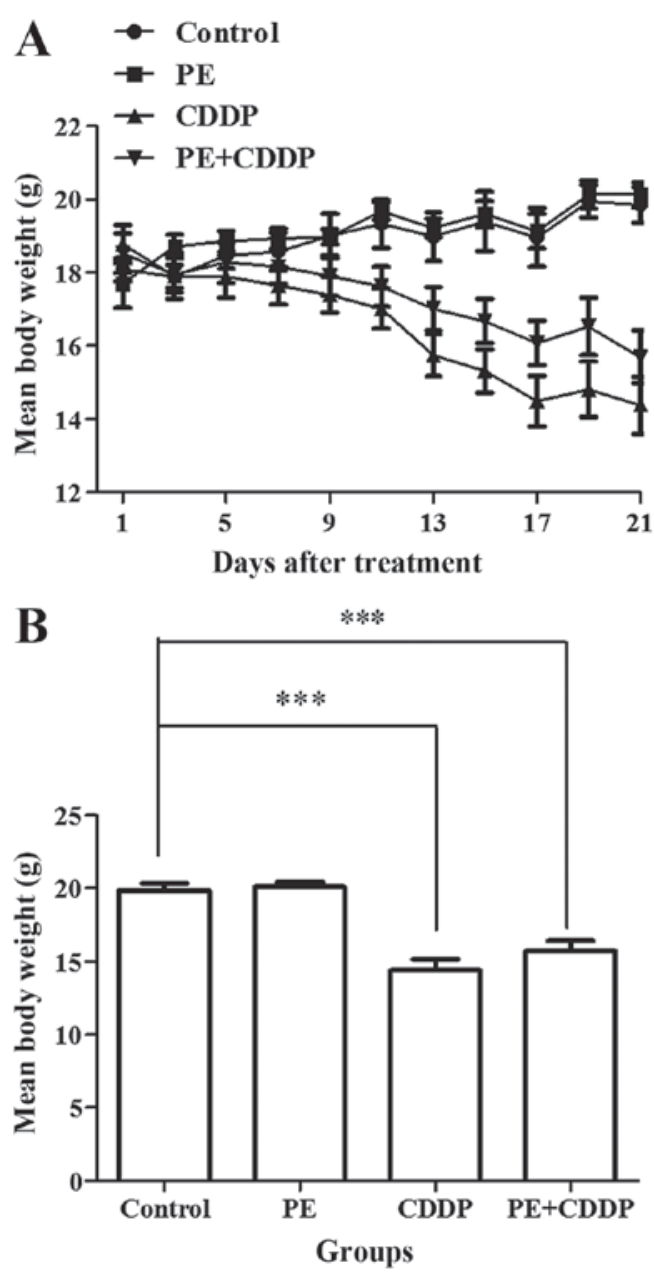

Figure 1. Changes in the body weight of nude mice following treatments. Eight mice were used in each group. (A) The changes in trend of mean body weight of mice in different groups following treatment. (B) The mean body weight of mice in different groups when treatment was over. The CDDP-treated mice had a remarkable body-weight loss compared with that observed in the PE-treated and control groups $(\mathrm{P}<0.001)$. The combined group has less body-weight loss than the CDDP-treated group, with no statistical significance. Bars represent the upper $95 \%$ confidence interval. ${ }^{* * *} \mathrm{P}<0.001$, for comparisons between mice treated with the combined treatment and mice treated with CDDP. PE, Pinelliapedatisecta; CDDP, cis-dichlorodiammineplatinum-II.

Effects of PE and CDDP on the expression of E6, p53 and apoptosis-associated proteins by western blot and immunohistochemistry analyses of tumor tissues. Since the human cervical cancer cell line CaSki contains the high-risk HPV16 genotype as described in the introduction of this cell line in ATCC (ATCC ${ }^{\circledR}$ CRL-1550 ${ }^{\mathrm{TM}}$ ), to further understand how PE and CDDP function to inhibit tumor growth synergistically, it was assessed whether the HPV E6/p53 signaling pathway was involved. The present study evaluated the protein expression of E6, p53, p21 and p27 in tumor masses resected from mice. As shown in Fig. 4, E6 had remarkably decreased protein expression levels upon co-treatment by PE and CDDP. By contrast, p53 expression was increased in the combined PE and CDDP treatment group, according to western blot and immunohistochemistry analyses. The Bcl-2 protein family controls apoptosis in mitochondria by balancing pro-and anti-apoptotic factors (11). The present study assessed the expression of the pro-apoptotic member Bax and the anti-apoptotic member 

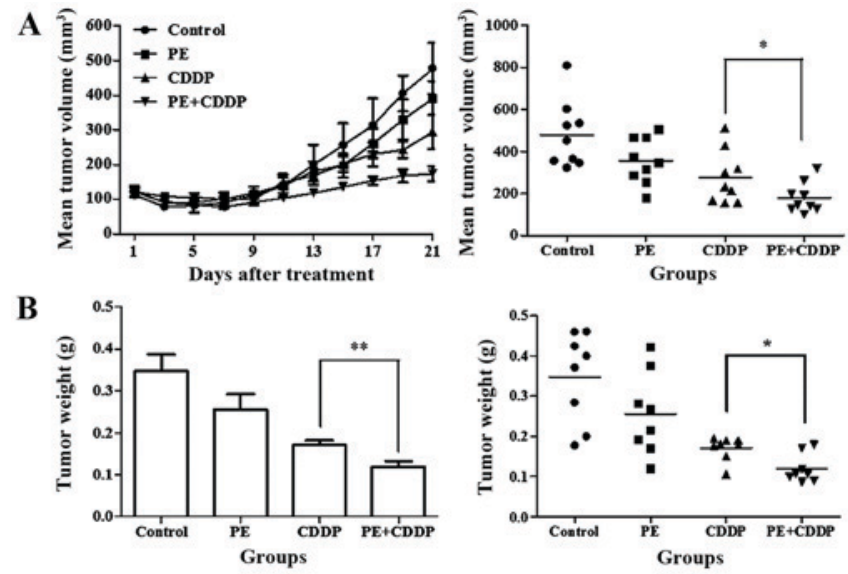

C

\begin{tabular}{cccc}
\hline Group & $\begin{array}{c}\text { Tumorvolume } \\
\left(\mathrm{mm}^{3}, \text { Mean } \pm \text { SD }\right)\end{array}$ & $\begin{array}{c}\text { Tumor weight } \\
(\mathrm{mg}, \text { Mean } \pm \text { SD })\end{array}$ & $\begin{array}{c}\text { Inhibition rate } \\
(\%)\end{array}$ \\
\hline Control & $498.5 \pm 157.1$ & $347.1 \pm 50.8$ & - \\
PE & $369.1 \pm 109.2$ & $255.9 \pm 45.2$ & 26.3 \\
CDDP & $288.8 \pm 127.6$ & $170.7 \pm 29.7$ & 50.8 \\
PE+CDDP & $161.7 \pm 52.4^{\circ}$ & $109.5 \pm 35.5^{*}$ & 68.4 \\
\hline
\end{tabular}

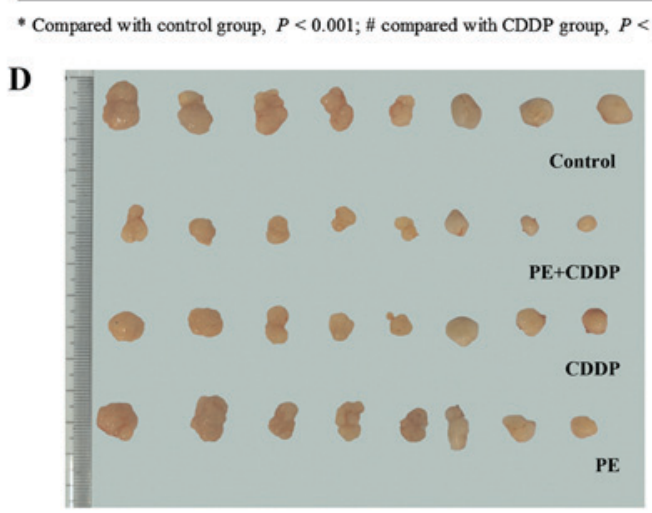

Figure 2. Effect of PE and CDDP alone and in combination on (A) tumor volume, (B) tumor weight and (C) tumor weight inhibitory ratio in subcutaneously CaSki cervical cancer xenografts of nude mice. Eight mice were used in each group. (A and B) The tumor burden was reduced significantly in the CDDP group, but not in the PE group. However, when PE was combined with CDDP, either tumor volume or tumor weight had a remarkable reduction compared with that displayed by the CDDP group ( $\mathrm{P}<0.05$ and $\mathrm{P}<0.01$, respectively). (C) The tumor weight inhibitory ratio of the combined group was larger than that of the CDDP $(\mathrm{P}<0.05)$ or the control $(\mathrm{P}<0.01)$ groups. (D) Images of the tumors from the subcutaneous nude-mouse model for the different groups. PE, Pinelliapedatisecta; CDDP, cis-dichlorodiammineplatinum-II; SD, standard deviation.

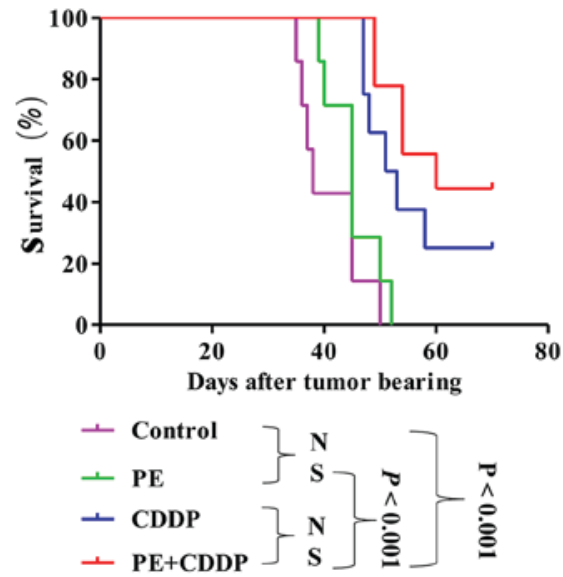

Figure 3. Survival curve of the mice in the four groups. Each group has 7 mice. Kaplan-Meier survival curve showing improved survival in tumor bearing mice treated with $\mathrm{CDDP}(\mathrm{P}<0.001)$ and the combination of $\mathrm{PE}$ and CDDP $(\mathrm{P}<0.001)$ compared with that exhibited by the untreated control group. However, compared with the CDDP-treated group, the combination group had no significantly longer lifespan $(\mathrm{P}>0.05)$. N.S., no significance; PE, Pinelliapedatisecta; CDDP, cis-dichlorodiammineplatinum-II.
Bcl-2. Bcl-2 protein expression was decreased significantly following combined PE and CDDP treatment. Caspases are the molecular machinery that directly drives apoptosis (12). Cleaved caspase- 9 and cleaved caspase- 3 expression was highly increased by treatment with PE or CDDP alone. The highest upregulation of apoptosis-associated proteins, including Apaf-1, Bax, and cleaved caspases-9 and -3, was observed in the combined PE and CDDP treatment group (Fig. 4). As shown in Fig. 5, tumors from the combined PE and CDDP treatment group exhibited the lowest cellular proliferation by $\mathrm{Ki}-67$ immunohistochemistry in xenografts.

\section{Discussion}

Cervical cancer has decreased to the fourth most frequently diagnosed type of cancer among females worldwide, primarily due to the widespread use of cervical screening programs $(1,13)$. However, $84.2 \%$ of new cases were diagnosed in developing countries, and $86.6 \%$ of mortalities occurred in developing countries (1). The age-standardized cervical 

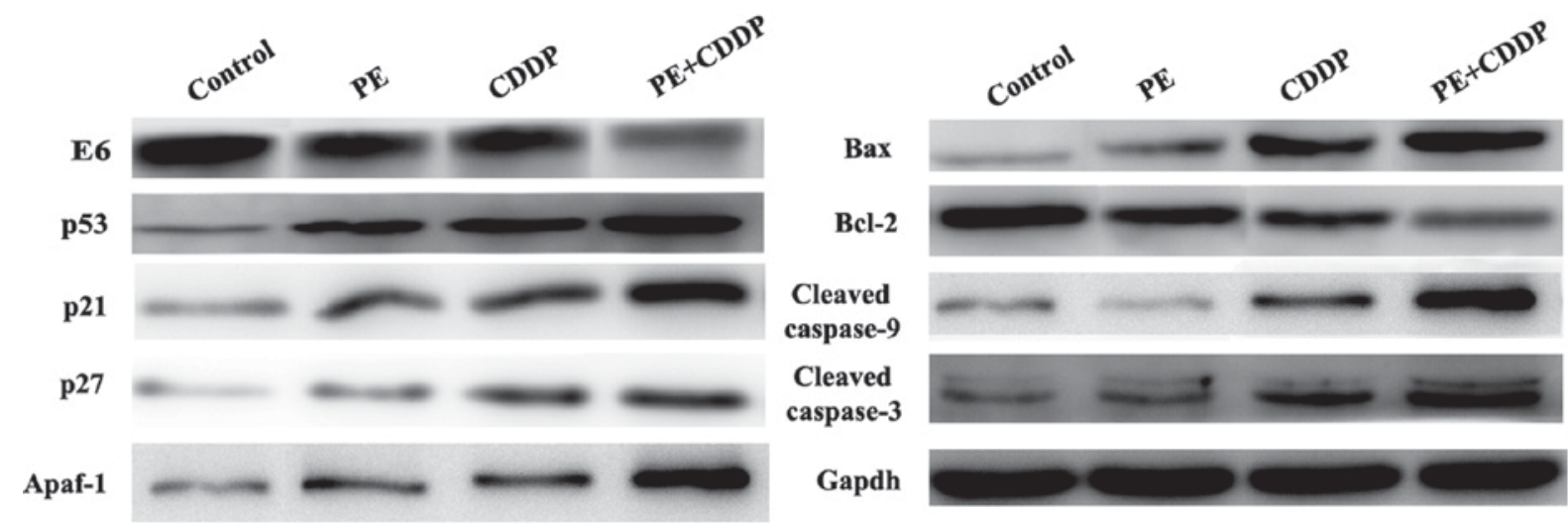

Figure 4. Western blot analysis of subcutaneously transplanted tumors. Western blot analysis of human papilloma virus E6, p53, p21, p27 Apaf-1and apoptosis-associated proteins expressed in xenografts from mice treated with PE and CDDP alone or in combination. GAPDH was used as a reference. PE, Pinelliapedatisecta; CDDP, cis-dichlorodiammineplatinum-II; Apaf-1, apoptosis protease activating factor 1; Bcl-2, B cell lymphoma/leukemia-2; Bax, Bcl-2-associated X protein.
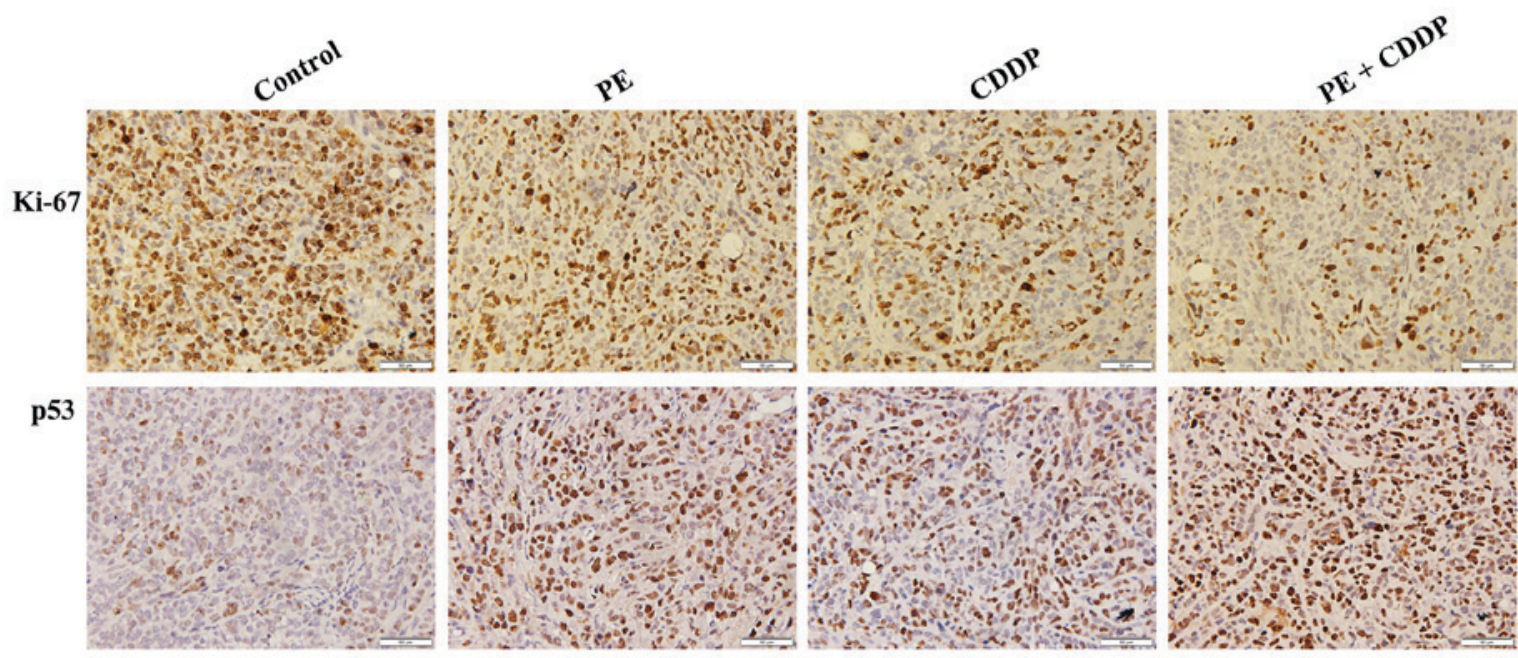

Figure 5. Expression of Ki-67 and p53 proteins in xenografts of mice (magnification, x400). Ki-67 immunohistochemistry revealed the level of cellular proliferation in the xenografts of mice treated with PE and CDDP alone or in combination. Scale bar=50 $\mu \mathrm{m}$. PE, Pinelliapedatisecta; CDDP, cis-dichlorodiammineplatinum-II.

cancer incidence in China was <5/100,000 from 1998 to 2002 (14), and the age-standardized 5-year (from 2005 to $2009)$ net survival was $60 \%(15,16)$. However, the incidence of cervical cancer mortality in China is currently among the highest worldwide (14). It is therefore still a big challenge for the Chinese government and for other less developed countries and areas to prevent this disease.

While the first-line treatment for early stages of cervical cancer is surgical excision, concomitant chemoradiotherapy based on CDDP is still the standard treatment for local advanced cervical cancer, particularly for distant control of the disease $(17,18)$. However, the chemotherapeutic use of CDDP is limited by severe side effects, including neurotoxicity, ototoxicity and in particular nephrotoxicity $(19,20)$. Due to the importance of CDDP chemotherapy for cancer patients, numerous studies have focused on protective strategies to alleviate the side effects of CDDP. Herbal and herbal-derived medicine has been recognized as an attractive approach for cancer therapy with few side effects $(21,22)$. Furthermore, evidence suggests that various herbal medicines have synergistic effects when combined with CDDP by enhancing its toxicity against cancer cells, prolonging the patients' survival time and preventing the side effects of chemotherapy (23-25). The purpose of the present study was to investigate in vivo whether PE had a synergistic cytotoxic effect when combined with CDDP, and to explore its potential mechanism.

To demonstrate that PE could increase the therapeutic activity of CDDP in vivo, a xenograft model with the human cervical cancer cell line CaSki was established in athymic female nude mice. Upon treatment, all tumor volumes were suppressed in the PE, CDDP and combined treatment groups. The combined treatment group exhibited the highest tumor suppression. As shown in Fig. 2A, the synergistic cytotoxic effect of PE and CDDP on tumor volume was first observed at day 7 after treatment, and achieved the highest effect at the end of the treatment. The same trend was also observed for tumor weight. The tumor weight inhibitory ratio in the combined treatment group reached $68.4 \%$, compared with $50.8 \%$ in the CDDP treatment group. Mice in the CDDP treatment group had the most severe weight loss. However, body weight in the 
PE treatment group was stable, with a slight increasing trend. Furthermore, body weight in the combined treatment group was higher than that in the CDDP treatment group. These results indicated that $\mathrm{PE}$ was safe and efficient in enhancing the cytotoxicity of CDDP in vivo, and it may decrease the effect of CDDP toxicity on weight loss.

As shown in Fig. 3, the mean survival time of mice in the combined treatment group was 60 days, which is longer than the 52 days observed with CDDP treatment alone. However, PE alone or combined with CDDP did not significantly prolong the survival time, likely because 70 days of tumor bearing was set as the cut-off point of survival time. A longer observational time or increased number of mice used in each group could have altered the present results. It is also possible that an increased dose of CDDP would have increased the mortality in the CDDP treatment group. Therefore, it cannot be excluded that combined PE and CDDP may significantly improve survival time.

Western blot assays were used in the present study to evaluate the expression of primary proteins in the HPV E6/ p53 signaling pathway. It is known that $50-60 \%$ of cervical cancers carry HPV16, and E6 (the main viral oncoprotein encoded by HPV16) serves a vital role in viral replication and oncogenic progression (26). E6 can regulate tumor growth signaling by forming specific complexes with tumor-suppressor gene products such as p53 (27). As a transcription factor, p53 serves a vital role in integrating cellular responses to various stimuli, including DNA damage and hypoxia, and once activated, p53 can stimulate the actions of various proteins involved in apoptosis and DNA repair $(28,29)$. When E6 binds to p53 and promotes its degradation through an ubiquitin-dependent proteasome pathway (30), the normal p53 function is lost (31). Importantly, reactivation of $\mathrm{p} 53$ can lead to inhibition of cell proliferation and induction of apoptosis in cervical cancer cells (32). Therefore, restoration of $\mathrm{p} 53$ function through inhibition of the E6/p53 signaling pathway has been considered an effective therapeutic approach for treating cervical cancer (33). As shown in Fig. 4, E6 expression was remarkably decreased when mice were co-treated with PE and CDDP, whilep53 expression was increased. Furthermore, the highest upregulation of p53-dependent apoptosis-associated proteins such as Bax and cleaved caspases-9 and -3 was observed in the combined treatment group, whereas $\mathrm{Bcl}-2$ expression was downregulated.

In conclusion, the present data and previous findings indicate that PE exerts a synergistic cytotoxic effect on tumor growth in vivo when combined with CDDP. The potential mechanism is likely associated with the inhibition of the E6/p53 signaling pathway to synergistically induce apoptotic signals in CaSki cells in vivo. The present study suggests a molecular basis for the potential application of PE and CDDP combination in the treatment of cervical cancer as a novel and pharmacologically safe chemotherapeutic strategy.

\section{Acknowledgements}

The present study was supported by the National Natural Science Foundation of China (grant no. 81373867 awarded to Dr Guiling Li).

\section{References}

1. Torre LA, Bray F, Siegel RL, Ferlay J, Lortet-Tieulent J and Jemal A: Global cancer statistics, 2012. CA Cancer J Clin 65: 87-108, 2015

2. DiSilvestro PA, Ali S, Craighead PS, Lucci JA, Lee YC, Cohn DE, Spirtos NM, Tewari KS, Muller C, Gajewski WH, et al: Phase III randomized trial of weekly cisplatin and irradiation versus cisplatin and tirapazamine and irradiation in stages IB2, IIA, IIB, IIIB, and IVA cervical carcinoma limited to the pelvis: A Gynecologic Oncology Group study. J Clin Oncol 32: 458-464, 2014.

3. Friedlander M and Grogan M; U.S. Preventative Services Task Force: Guidelines for the treatment of recurrent and metastatic cervical cancer. Oncologist 7: 342-347, 2002.

4. Travis LB, Fossa SD, Sesso HD, Frisina RD, Herrmann DN Beard CJ, Feldman DR, Pagliaro LC, Miller RC, Vaughn DJ, et al: Chemotherapy-induced peripheral neurotoxicity and ototoxicity: New paradigms for translational genomics. J Natl Cancer Inst 106: pii: dju044, 2014.

5. Chen SJ, Kuo CC, Pan HY, Tsou TC, Yeh SC and Chang JY: Mechanistic basis of a combination D-penicillamine and platinum drugs synergistically inhibits tumor growth in oxaliplatin-resistant human cervical cancer cells in vitro and in vivo. Biochem Pharmaco 195: 28-37, 2015.

6. Li CJ, Xu YM and Sun YL: Research on anti-cervical cancer component of Pinellia pedatisecta Schott. J Shanghai Med Univ 8: 421-423, 1981 (In Chinese).

7. Chemistry Department of Basic Research Center, Obstetrics and Gynecology Hospital. Research of Pinellia pedatisecta Schott on cervical cancer. Shanghai Med J 1: 13-16, 1978 (In Chinese).

8. Li GL, Jiang W, Xia Q, Chen SH, Ge XR, Gui SQ and Xu CJ: HPV E6 down-regulation and apoptosis induction of human cervical cancer cells by a novel lipid-soluble extract (PE) from Pinellia pedatisecta Schott in vitro. J Ethnopharmacol 132: 56-64, 2010.

9. Li GL, Gui SQ, Zhu DH, Chen SH and Ye Y: Effects of pinellia extraction only or combined with cisplatin on growth of HeLa cells of cervical cancer. Fudan Univ J Med Sci 34: 869-872, 2007.

10. Spielmann H: FRAME Annual Lecture. International co-operation: An essential requirement for replacing animal toxicity tests. Altern Lab Anim 29: 637-648, 2001.

11. Hatok J and Racay P: Bcl-2 family proteins: Master regulators of cell survival. Biomol Concepts 7: 259-270, 2016.

12. Matt $S$ and Hofmann TG: The DNA damage-induced cell death response: A roadmap to kill cancer cells. Cell Mol Life Sci 73: 2829-2850, 2016.

13. Harlan LC and Warren JL: Global survival patterns: Potential for cancer control. Lancet 385: 926-928, 2015.

14. Shi JF, Canfell K, Lew JB and Qiao YL: The burden of cervical cancer in China: Synthesis of the evidence. Int J Cancer 130: 641-652, 2012.

15. Allemani C, Weir HK, Carreira H, Harewood R, Spika D, Wang XS, Bannon F, Ahn JV, Johnson CJ, Bonaventure A, et al: Global surveillance of cancer survival 1995-2009: Analysis of individual data for $25,676,887$ patients from 279 population-based registries in 67 countries (CONCORD-2). Lancet 385: 977-1010, 2015.

16. Ferlay J, Forman D, Mathers CD and Bray F: Breast and cervical cancer in 187 countries between 1980 and 2010. Lancet 379: 1390-1391, 2012.

17. Jelavić TB, Miše BP, Strikic A, Ban M and Vrdoljak E: Adjuvant chemotherapy in locally advanced cervical cancer after treatment with concomitant chemoradiotherapy-room for improvement? Anticancer Res 35: 4161-4165, 2015.

18. Penson RT, Huang HQ, Wenzel LB, Monk BJ, Stockman S, Long HJ III, Ramondetta LM, Landrum LM, Oaknin A, Reid TJ, et al: Bevacizumab for advanced cervical cancer: Patient-reported outcomes of a randomised, phase 3 trial (NRG Oncology-Gynecologic Oncology Group protocol 240). Lancet Oocol 16: 301-311, 2015 .

19. Sprowl JA, Lancaster CS, Pabla N, Hermann E, Kosloske AM, Gibson AA, Li L, Zeeh D, Schlatter E, Janke LJ, et al: Cisplatin-induced renal injury is independently mediated by OCT2 and p53. Clin Cancer Res 20: 4026-4035, 2014.

20. Karasawa T and Steyger PS: An integrated view of cisplatin-induced nephrotoxicity and ototoxicity. Toxicol Lett 237: 219-227, 2015.

21. Hirchaud F, Hermetet F, Ablise M, Fauconnet S, Vuitton DA, Prétet JL and Mougin C: Isoliquiritigenin induces caspase-dependent apoptosis via downregulation of HPV16 E6 expression in cervical cancer Ca Ski cells. Planta Med 79: 1628-1635, 2013. 
22. Peng Y, Guo CS, Li PX, Fu ZZ, Gao LM, Di Y, Ju YK, Tian R and Xue JJ: Immune and anti-oxidant functions of ethanol extracts of Scutellaria baicalensis Georgi in mice bearing U14 cervical cancers. Asian Pac J Cancer Prev 15: 4129-4133, 2014.

23. Wang LH, Li Y, Yang SN, Wang FY, Hou Y, Cui W, Chen K, Cao Q, Wang S, Zhang TY, et al: Gambogic acid synergistically potentiates cisplatin-induced apoptosis in non-small-cell lung cancer through suppressing NF- $\mathrm{KB}$ and MAPK/HO-1 signalling. Br J Cancer 110: 341-352, 2014.

24. Li X, Huang T, Jiang G, Gong W, Qian H and Zou C: Synergistic apoptotic effect of crocin and cisplatin on osteosarcoma cells via caspase induced apoptosis. Toxicol Lett 221: 197-204, 2013.

25. Chen Y, Liu JM, Xiong XX, Qiu XY, Pan F, Liu D, Lan SJ, Jin S, Yu SB and Chen XQ: Piperlongumine selectively kills hepatocellular carcinoma cells and preferentially inhibits their invasion via ROS-ER-MAPKs-CHOP. Oncotarget 6: 6406-6421, 2015.

26. Tan S, de Vries EG, van der Zee AG and de Jong S: Anticancer drugs aimed at E6 and E7 activity in HPV-positive cervical cancer. Curr Cancer Drug Targets 12: 170-184, 2012.

27. Münger K, Scheffner M, Huibregtse JM and Howley PM: Interactions of HPV E6 and E7 oncoproteins with tumour suppressor gene products. Cancer Surv 12: 197-217, 1992.

28. Bradner JE: Cancer: An essential passenger with p53. Nature 520 : 626-627, 2015
29. Guimarães-Camboa N, Stowe J, Aneas I, Sakabe N, Cattaneo P, Henderson L, Kilberg MS, Johnson RS, Chen J, McCulloch AD, et al: HIF1 $\alpha$ represses cell stress pathways to allow proliferation of hypoxic fetal cardiomyocytes. Dev Cell 33: 507-521, 2015.

30. Lee D, Kwon JH, Kim EH, Kim ES and Choi KY: HMGB2 stabilizes 553 by interfering with E6/E6AP-mediated p53 degradation in human papillomavirus-positive HeLa cells. Cancer Lett 292: 125-132, 2010.

31. Zhang W, Liu Y, Zhao N, Chen H, Qiao L, Zhao W and Chen JJ: Role of Cdk1 in the p53-independent abrogation of the postmitotic checkpoint by human papillomavirus E6. J Virol 89: 2553-2562, 2015

32. Kochetkov DV, Il'Inskaia GV, Komarov PG, Strom E, Agapova LS, Ivanov AV, Budanov AV, Frolova EI and Chumakov PM: Transcriptional inhibition of human papilloma virus in cervical carcinoma cells reactivates functions of the tumor suppressor p53. Mol Biol (Mosk) 41: 515-523, 2007 (In Russian).

33. Münger K and Howley PM: Human papillomavirus immortalization and transformation functions. Virus Res 89: 213-228, 2002. 